\title{
^UCLPRESS
}

Article title: Key opportunities and challenges for the use of big data in migration research and policy Authors: Lydia Franklinos[1], Rebecca Parrish[2], Rachel Burns[3], Andrea Caflisch[4], Bishawjit Mallick[5], Taifur Rahman[6], Vasileios Routsis[7], Ana Sebastián López[8], Andrew Tatem[9], Robert Trigwell[10]

Affiliations: Institute for Global Health, University College London, London, UK; Centre for Biodiversity and Environment Research, Department of Genetics, Evolution and Environment, University College London, London, UK[1], Institute for Global Health, University College London, London, UK; Institute of Environment, Health and Societies, Brunel University, London, UK[2], Centre of Public Health Data Science, Institute of Health Informatics, University College London, London, UK[3], United Nations' Displacement Tracking Matrix, International Organization for Migration, International Organization for Migration, Juba, South Sudan[4], CU Population Center, Institute of Behavioral Science, University of Colorado Boulder Campus, Boulder, CO, USA; Faculty of Environmental Sciences, Technische Universität Dresden, Dresden, Germany[5], Health Management BD Foundation, Sector 6, Uttara, Dhaka, Bangladesh; Adjunct Faculty, Department of Public Health, North South University, Dhaka, Bangladesh[6], Department of Information Studies, University College London, London, UK[7], GMV Innovating Solutions Ltd, HQ Building, Thomson Avenue, Harwell Campus, Didcot, UK[8 WorldPop, School of Geography and Environmental Science, University of Southampton, Southampton, UK[9], United Nations' Displacement Tracking Matrix, International Organization for Migration, United Nations, London, UK[10]

Orcid ids: 0000-0002-5766-3986[1]

Contact e-mail: lydia.franklinos.16@ucl.ac.uk

License information: This is an open access article distributed under the terms of the Creative Commons Attribution License (CC BY) 4.0 https://creativecommons.org/licenses/by/4.0/, which permits unrestricted use, distribution and reproduction in any medium, provided the original author and source are credited.

Preprint statement: This article is a preprint and has not been peer-reviewed, under consideration and submitted to UCL Open: Environment Preprint for open peer review.

Funder: UCL Grand Challenges, UCL, London, UK

DOI: $10.14324 / 111.444 / 000042 . v 1$

Preprint first posted online: 18 June 2020

Keywords: Big data, migration, cross-disciplinary research, policy, humanitarian, environment, displacement, climate change, health, data security, Environmental modelling, Public policymaking, Environmental justice and inequality/inequity, Statistics, Health and climate change 
London

WC1N 1EH

Dear Editorial Staff,

\section{Key opportunities and challenges for the use of big data in migration research and policy}

I am writing to submit the above manuscript for consideration for publication in UCL Open:

Environment, as previously discussed with lan Caswell and Professor Dan Osborn.

Migration is high on the global political agenda, with one billion people recorded as having migrated in 2018 alone. Such levels of migration have great implications for global health, the global development agenda and political discourse at all levels of society. Meeting the needs of migrant populations requires accurate data on who is moving, where to and from, and what is driving their movements. However, current information on migrant populations is relatively scarce, leading to the UCL-Lancet Commission on Migration and Health to propose 'big data' (from mobile phone data to satellite data) as a potential solution to help address these knowledge gaps.

In response to the Commission's call, we held a cross-disciplinary workshop in London, UK in July 2019, bringing together UN representatives, humanitarian NGOs, policymakers and academics to facilitate knowledge exchange and identify the key opportunities and challenges for the implementation of big data in migration research. This workshop was supported by a UCL Grand Challenges grant for projects focusing on migration and displacement.

Here, we provide a summary of key discussion points and conclusions identified in the workshop to assist migration experts in deciding whether the use of big data is appropriate for their work. We also aim to stimulate discussion about the potential of this approach in aiding future migration research and policy and the needs of migrant populations globally, especially given ongoing high-level political narratives about migration, environmental drivers, and migrant health. Furthermore, the workshop was a highly interdisciplinary event and we take the opportunity to discuss how to develop further cross-disciplinary solutions to migration research.

I confirm that I have agreement from all authors to submit this paper and that the manuscript is not submitted elsewhere and is original.

I look forward to your response in due course.

Yours faithfully, 
Key opportunities and challenges for the use of big data in migration research and policy

Lydia H.V. Franklinos ${ }^{1,2}$, Rebecca Parrish ${ }^{1,3}$, Rachel Burns ${ }^{4}$, Andrea Caflisch ${ }^{5}$, Bishawjit Mallick $^{6,7}$, Taifur Rahman ${ }^{8,9}$, Vasileios Routsis ${ }^{10}$, Ana Sebastián López ${ }^{11}$, Andrew J. Tatem ${ }^{12}$, Robert Trigwell ${ }^{13}$.

1. Institute for Global Health, University College London, London, UK

2. Centre for Biodiversity and Environment Research, Department of Genetics, Evolution and Environment, University College London, London, UK

3. Institute of Environment, Health and Societies, Brunel University, London, UK

4. Centre of Public Health Data Science, Institute of Health Informatics, University College London, London, UK

5. United Nations' Displacement Tracking Matrix, International Organization for Migration, International Organization for Migration, Juba, South Sudan

6. CU Population Center, Institute of Behavioral Science, University of Colorado Boulder Campus, Boulder, CO, USA

7. Faculty of Environmental Sciences, Technische Universität Dresden, Dresden, Germany

8. Health Management BD Foundation, Sector 6, Uttara, Dhaka, Bangladesh

9. Adjunct Faculty, Department of Public Health, North South University, Dhaka, Bangladesh

10. Department of Information Studies, University College London, London, UK

11. GMV Innovating Solutions Ltd, HQ Building, Thomson Avenue, Harwell Campus, Didcot, UK

12. WorldPop, School of Geography and Environmental Science, University of Southampton, Southampton, UK

13. United Nations' Displacement Tracking Matrix, International Organization for Migration, United Nations, London, UK

\section{Abstract}

Migration is one of the defining issues of the 21 st century. Better data is required to improve understanding about how and why people are moving, target interventions and support evidence-based migration policy. Big data, defined as large, complex data from diverse sources, has been proposed as a solution to help address current gaps in knowledge. The authors participated in a workshop held in London, UK, in July 2019, that brought together experts from the UN, humanitarian NGOs, policy and academia to develop a better understanding of how big data could be used for migration research and policy. We identified six key areas regarding the application of big data in migration research and policy: accessing and utilising data; integrating data sources and knowledge; understanding 
environmental drivers of migration; improving healthcare access for migrant populations; ethical and security concerns; and addressing political narratives. We advocate the need for increased cross-disciplinary collaborations to advance the use of big data in migration research whilst safeguarding vulnerable migrant communities.

\section{Keywords}

Big data; migration; cross-disciplinary research; policy; humanitarian; environment; displacement; climate change; health; data security.

\section{Introduction}

With the number of global refugees reaching the highest levels since the second World War (1) and one billion migrants recorded in 2018 alone (2), human migration is high on the global political agenda. The UCL-Lancet Commission on Migration and Health (2) and the UN Global Compact on Migration (3) have called for improved data to understand drivers of migration, target interventions and support evidence-based migration policy. The application of big data in migration research and policymaking has been proposed as a possible solution to help address these knowledge gaps $(2,4)$. Big data refers to large, complex data from varied sources, ranging from social media and mobile phone data (Figure 1), to electronic health records and satellite data, and has the potential to provide new sources of information for migration research $(5,6)$. Previous studies have used big data to predict patterns of human movement during natural disasters (7) and track movement in near real-time (8), quantify migration at national scales (9-13), guide and evaluate humanitarian interventions (14) and examine the effects of human movement on disease transmission (15). In addition, satellite-based earth observation data has been used to map the relationship between environmental change and human movement $(16,17)$, model subnational migration flows (18) and inform policy decisions $(17,19,20)$. Despite the immense opportunity big data can provide for migration research and policy, several challenges have hindered its widespread implementation $(2,4)$.

In response to the call for increased collaboration (2) and improved research on ways to utilise big data sources in the field of migration (4), we participated in a cross-disciplinary workshop in London, UK $3^{\text {rd }}$ July 2019, bringing together UN representatives, humanitarian NGOs, policymakers and academics to facilitate knowledge-exchange and identify the key opportunities and challenges for the implementation of big data in migration research. Here, we provide a summary of key discussion points identified in the workshop via presentations, 
panel discussions and break-out groups in which participants explored different topics and possible solutions. We provide major conclusions from the workshop to assist migration experts in deciding whether the use of big data is appropriate for their work and to stimulate discussion about the potential of this approach in aiding migration research and policy, and the needs of migrant populations globally. In particular, the outcomes of this workshop may provide a timely resource for the recently launched Lancet Migration, a global collaboration of migration experts that aims to address evidence gaps and drive policy change in the field (21).

\section{Opportunities and challenges relating to big data}

We identified six important topics for the application of big data in migration research and policy which we summarise here and in Table 1.

\section{Accessing and utilising big data}

The first issue focused on the access, awareness and expertise required for big data use. The application of big data is often hindered by the fact that many big data sources such as mobile phones, internet-based platforms and other digital devices are managed by private companies who collect the data for business purposes. Therefore, costs associated with accessing big data and issues of ownership are significant barriers to its use (22). Big data generation will vary geographically, and may be reduced in many high mobility contexts where infrastructure (i.e., cell towers, wi-fi connection and electronic bank transfer services) is less established. In addition, there are significant issues around the potential extraction of sensitive information contained in big data $(23,24)$ and data sources are often fragmentated across disciplines which reduces the awareness of available datasets (25). Accounting for multiple biases and the complex analyses required to interpret the data are further examples of methodological difficulties associated with the use of big data $(6,26)$.

Workshop discussions highlighted the importance of understanding how, why and when the data were collected to identify potential gaps and biases, therefore ensuring it can be used effectively. There is great need for more centralised repositories of data, projects and publications as such as The Humanitarian Data Exchange (27), to promote knowledgesharing, collaborations and inform evidence-based programming. Increased partnerships between governments, international agencies, civil society, and the private sector are also required to improve data access and ensure the optimum exploitation of available data and technologies. Furthermore, capacity building in countries or organisations with an interest in big data analysis is needed to support cross-disciplinary research and improve specialist 
knowledge in certain regions. This could be achieved via collaborations with relevant partners and agencies such as demonstrated with the United Nations Economic Commission for Europe's (UNECE) Big Data Sandbox which provided a platform for statistical organisations to collaborate and learn to use big data analytics (28). However, there may be ethical considerations for private-public partnerships. For example, published commentaries have voiced fears over the partnership between the UN's World Food Programme and the data analytics company Palantir which may have serious consequences for the privacy and security of aid recipients due to the company's links to US intelligence agencies (29).

\section{Integrating data sources and knowledge}

The second topic concerned the integration of data and knowledge across disciplines. The main source of data for migration statistics originates from traditional methods such as household surveys recorded at local scales and national population estimates (Figure 2), as well as data on forced displacement collected through key informant networks (4). Big data sources have the potential to complement traditional data and address significant spatial and temporal gaps via updating migration statistics in an accurate and low-cost way $(4,10)$. For example, analysis of mobile phone call detail records (CDRs) can be used to replicate national internal migration statistics and complement outputs from censuses (10). However, integrating migration data from traditional methods with varied sources of big data requires new methodology that considers complex interactions over differing geographic and temporal scales. Indeed, the slow adoption of big data analyses in the humanitarian sector is partly due to a lack of expertise in how to apply these approaches in operational settings (30). Workshop participants discussed the need to bridge the gap between experts on the ground collecting the data via traditional methods and big data analysts via increased transdisciplinary training and collaborations. A recent workshop hosted by the International Organization for Migration (IOM) and the German Federal Foreign Office concluded that "greater cooperation and engagement among stakeholders" both within and external to the migration sector are required to inform decision making (31). If we are to integrate different data sources effectively, a collaborative cross-disciplinary approach is required to ensure we understand the data and how they can be used to deepen our understanding of the drivers and impacts of migration. This approach is practiced in "Data Collaboratives"; collaborative projects in which different sectors including private companies, research institutions, and government agencies collaborate to enable data exchange and help solve public problems (32). NetHope is an example of a Data Collaborative project which helped to integrate data 
sources and produce maps of connectivity sites across Puerto Rico to assist in delivering aid in the aftermath of Hurricane Maria (33).

\section{Understanding environmental drivers of migration}

The third topic considered the use of big data in informing environmental drivers of migration such as natural disasters and climate change (34). Currently, there is no internationally agreed definition for "environmental migrant" despite it being required to collect long-term data and guide the policies of governments and international agencies. The IOM have proposed a broad working definition (35) which importantly considers that environmental migration might be triggered both by sudden-onset disasters (36), such as earthquakes and cyclones, and slower environmental change processes, such as desertification and sea-level rise. In the context of slow-onset disasters and gradual environmental change, migration is often difficult to quantify since it can be hidden behind more immediate socioeconomic drivers such as poverty or political processes (37). Human mobility can improve resilience and attenuate the negative outcomes of environmental degradation, but poverty, disability and social exclusion may limit people's ability to resort to migration as an adaptation strategy (38). When used in combination with traditional datasets, big data has the potential to identify these vulnerable populations that are unable to migrate in response to environmental change. Satellite data is a particularly valuable resource in migration analysis as it enables the systematic, consistent and accurate monitoring of areas (even if remote or inaccessible) that are affected by conflicts or by anthropic or natural hazards. Indeed, satellite-based technologies are key to analysing climate change effects and predicting environmental-led migration $(39,40)$. This is particularly useful in contexts where administrative and health records are lacking and there is limited mobile network or internet connection. However, satellite data alone may not provide the spatial resolution required to capture needs, and cannot reveal the lived experiences of migrants required to inform actions. In this case, satellite data can be combined with traditional datasets to identify the location of internally displaced people, as performed by IOM's Displacement Tracking Matrix in response to flooding in South Sudan in 2019 (41). One of the most valuable aspects of satellite-based analyses is the capability for retrospective analysis which is required to detect changing patterns across space and time and to inform predictions. However, a recent review stated that current initiatives do not exploit the full possibilities of satellite-based earth observation in migration with a lack of services offering the systematic flow of detailed information to researchers, managers and migration analysts (42). One of the main gaps identified was that currently consolidated satellite-based monitoring systems work at regional scales which it is 
217 often too coarse to understand the specificities of particular communities, thus unable to

218 inform sub-national policies design, implementation and monitoring.

\section{Improving healthcare access for migrant populations}

A fourth area of discussion focussed on the potential for big data to improve migrant health via identification of vulnerable groups, increased access to healthcare and in informing evidence-based health interventions. Often there is limited information on undocumented migrants and vulnerable groups (i.e., unaccompanied children, people with disabilities and members of the LGBTI community) in traditional datasets such as semi-structured interviews and surveys (2). Discussions focused on whether big data could provide information about these groups, their health and differing healthcare needs. In addition, it was suggested that the healthcare needs of migrants settled in countries such as the UK could also be improved by big data analysis, for example via a general migrant longitudinal study such as the cohort studies performed by the UK Economic and Social Research Council (42). A further question focused on the potential for big data to support on-theground activities, helping to address the immediate health needs of displaced persons and to predict potential disease outbreaks. During an Ebola virus disease outbreak in the Democratic Republic of Congo, IOM employed Flow Monitoring Registry surveys to gather anonymous information about people on the move at key transit points to inform public health interventions (43). Using this system, hundreds of thousands of individual journeys were tracked, making the datasets a hybrid between traditional randomised surveys and big data. There are also potential applications for big data in implementing evidence-based health interventions that need to be explored, specifically in informing cost-benefit analysis and analysis of intervention effectiveness.

\section{Ethical, privacy and security concerns}

The fifth topic focussed on ethical, privacy and security concerns regarding the use of big data in migration research. The collection of personal data including migrant status is a contentious issue. There are concerns that information on personal migration status may create or increase existing discriminatory practices in society such as provision of healthcare and access to state funds, or that mobile tracking devices may be used against a migrant to forcibly return them to a previous location (2). Ethics in the context of big data in migration may be considered in several ways. First, it may relate to the way in which the research is conducted and whether there has been consideration for data privacy and security. Secondly, it could 
refer to decision-making regarding migrants with consideration for their lived experience, especially in humanitarian situations. A recent report on migration noted that discussions on ethics often focus on the legal aspects of data protection rather than understanding how the results of analyses may detrimentally impact affected populations and counter the humanitarian principles to "do no harm" (31). Furthermore, data protection measures are often focussed on personal data (e.g. General Data Protection Regulation in EU) and do not consider group data protection needed to work with vulnerable groups (44).

It is important to consider who benefits from the use of big data sources in migration research. At the individual level, migrants may not wish for additional data to be gathered about them and may perceive no benefits of the process (45). However, at the community level, such data and analysis may help to address the health needs of migrants more generally. Certainly, there will be benefits to the academic community seeking to study migrant health needs and to decision-makers seeking evidence-based solutions. Pursuit of these research and policy goals can result in overlooking the individual rights and raise ethical issues for many vulnerable people (45). Furthermore, forcibly displaced people fleeing persecution may have little trust in authorities and therefore be less willing to seek healthcare or consent to having their data collected. This creates a barrier for healthcare professionals, humanitarian workers and researchers who wish to respect the rights of the individual, whilst deriving a better understanding of migration pathways and healthcare needs. Workshop discussions highlighted the power imbalance between various parties involved; those seeking data including governments and academics (often from the Global North with inherent biases and power), and those the data is being sought from who are often vulnerable persons in precarious or dangerous situations, many originating in the less represented Global South (46). Even with applying advanced safeguarding practices and aggregated outputs, researchers may still be reluctant to apply big data analysis for migration research as policymakers often tend to have their own agendas and may use the methods and deliverables in ways not intended or anticipated by the research authors.

\section{Addressing political narratives}

The final topic concerned the role of big data in high level political narratives around migration. With ongoing antimigrant rhetoric existing at all levels of government and society, migrant research has the opportunity and mandate to address such political narratives. There are many examples of authorities treating migrants as political pawns or as statistical figures (47). Therefore, it is imperative that big data is not used to further discriminate against migrant communities or to target certain populations, but rather to support inclusive and fair migration 
governance. An example discussed within the workshop was the Sentinel project which is an

287 NGO that works to gather and disseminate trusted information to local people and governments in order to counter the spread of misinformation, antimigrant rhetoric and prevent resultant hate crime and genocides (48). Participants also deliberated whether the increased evidence provided by big data would be instructive and powerful enough to overcome political and social biases associated with the topic. Given the highly political nature and high stakes of migration policy for governments and the international community, more evidence may alone be insufficient to achieve multilateral, progressive action. It is worth therefore considering other factors contributing to the political discourse and designing strong, crossdisciplinary communication tactics to support maximum impact of evidence. Furthermore, it is worth considering how paucity in migration data has helped to shape public and media perceptions of global migration patterns to date, and whether big data could be used to address these perceptions.

\section{Discussion}

301

The application of big data in migrant research shows much promise in addressing the current gaps in knowledge. Big data sources can help to update internal migration statistics by addressing the significant gaps in quantity and quality of data collected from traditional methods $(4,10)$. When combined with field-level data derived from household surveys and key-informant networks, big data can be used to detect how sudden onset natural disasters and gradual environmental change (e.g. desertification and sea-level rise associated with climate change) impact migration patterns. This can help to inform planning and scenario building, as well as contributing to a more comprehensive definition of "environmental migrant" which is critical for migration policy with in the context of ongoing environmental change. In addition, it has a potential application in considering the differing healthcare needs of migrants as well as identifying vulnerable populations unable to migrate due to environmental change. There is also scope for big data to inform evidence-based health interventions for migrant populations in everyday and emergency (including displacement) settings. Yet despite the vast opportunities that big data present, there are some important areas to consider before using these varied and complex data sources. Increased cross-disciplinary partnerships are required to improve data access, knowledge-sharing and capacity building across sectors and regions. In addition, a collaborative cross-disciplinary approach is required to ensure the different datasets are understood and to develop new methodologies to integrate data sources and identify complex interactions that influence how and why people are moving. Furthermore, 
321 should be applied needs to be addressed so analyses can be effective (31). International 322 legislation is required to sufficiently address how migrant data should be collected and used 323 to ensure ethical conduct by data gatherers and owners and the safeguarding of human rights, 324 even in sensitive migration contexts (49). The United Nations Development Group (49) and 325 Office for the Coordination of Humanitarian Affairs (50) provide guidelines for safe and ethical 326 data management in humanitarian situations however, there is no legal enforcement of these 327 practices. Although researchers would like quicker and easier access to data, workshop 328 discussions challenged whether the process should be hastened, suggesting that 329 administrative obstacles force researchers to duly consider whether additional data is 330 necessary and beneficial to the current state of knowledge, given the risks and trade-offs that 331 must be made. A key output of the workshop was a consensus that researchers and decision332 makers must first ask why they require additional data and whether this is what all parties, 333 particularly migrants, would want. As well as data protection issues, it is also imperative to 334 understand the potential harmful impact of analyses on vulnerable migrant populations (31). 335 It is especially important that big data is not used to further discriminate or target migrant populations considering current antimigrant political narratives.

337 In pursuit of cross-disciplinary collaboration, the workshop brought together a range of 338 representatives from the UN, government, humanitarian agents and academics from a range 339 of backgrounds. Cross-sector engagement in the workshop was difficult to achieve which 340 may be due to differences in the objectives of different sectors, as well as the language of 341 engagement used. We trialled different methods to stimulate interdisciplinary work including 342 the use of business canvases (51) to explore and present solutions to questions. This 343 approach was useful for stimulating debate within the groups and producing well-considered 344 outputs. However, future interdisciplinary events would benefit from the development of 345 methods that consider the language styles and information sharing techniques of different 346 disciplines and thus facilitate effective communication and knowledge-sharing $(4,31,52,53)$.

347 Overall, the workshop highlighted the benefits of cross-disciplinary work, enabling the 348 identification of key topics from a variety of angles and providing meaningful and effective 349 outputs. Furthermore, we hope this workshop assists in cultivating a future transdisciplinary 350 approach to migration research, whereby there is a move beyond the collaboration of 351 individual disciplinary perspectives to develop curriculum integration that organises 352 knowledge production in the context of real-world problems (54). 
Table 1. Opportunities and challenges for the use of big data in migration research and policy.

\begin{tabular}{|c|c|}
\hline Topics & Key research and policy questions \\
\hline Accessing and utilising big data & $\begin{array}{l}\text { How can we improve access to big data sources? } \\
\text { How can we enhance awareness of available data? } \\
\text { How can we develop the expertise required to use big data } \\
\text { across disciplines? }\end{array}$ \\
\hline $\begin{array}{l}\text { Integrating data sources and } \\
\text { knowledge }\end{array}$ & $\begin{array}{l}\text { How can we produce more detailed and recent migration } \\
\text { statistics using big data? } \\
\text { How can we best integrate data from different sources? } \\
\text { How do we manage fragmented data sources across varied } \\
\text { spatial and temporal scales? } \\
\text { How can we develop a collaborative cross-disciplinary approach } \\
\text { to address the challenges in the field of migration? }\end{array}$ \\
\hline $\begin{array}{l}\text { Understanding environmental } \\
\text { drivers of migration }\end{array}$ & $\begin{array}{l}\text { How can big data be used to assess the ongoing impact of } \\
\text { climate change on migration? } \\
\text { Can big data help to identify populations that are vulnerable to } \\
\text { environmental change? } \\
\text { How can big data be used to predict mass migration events due } \\
\text { to environmental change? }\end{array}$ \\
\hline $\begin{array}{l}\text { Improving healthcare access for } \\
\text { migrant populations }\end{array}$ & $\begin{array}{l}\text { How can big data be used to address the immediate health } \\
\text { needs of displaced persons in camps? } \\
\text { How can big data help us learn more about undocumented } \\
\text { migrants, their health and healthcare needs? } \\
\text { How can big data be used to implement evidence-based health } \\
\text { interventions; e.g. cost-benefit analysis, analysis of intervention } \\
\text { effectiveness? }\end{array}$ \\
\hline $\begin{array}{l}\text { Ethical, privacy and security } \\
\text { concerns }\end{array}$ & $\begin{array}{l}\text { What is meant by ethics in the context of big data in migration } \\
\text { research? } \\
\text { Who benefits from the use of big data (migrants at individual or } \\
\text { community level, academic community, policymakers)? } \\
\text { How do power imbalances influence the use of big data? } \\
\text { How can we achieve ethical data usage? }\end{array}$ \\
\hline Addressing political narratives & $\begin{array}{l}\text { How can we prevent the use of big data for the discrimination of } \\
\text { certain populations? } \\
\text { What role could big data have in addressing the negative } \\
\text { political narratives around migration? }\end{array}$ \\
\hline
\end{tabular}


Figure 1. Key statistical indicators for global big data use. The number of users and portion of the population that has access (penetration) to the internet, mobile phones, social media and mobile social media. Data were accessed via the Global Digital Report 2019 (55).

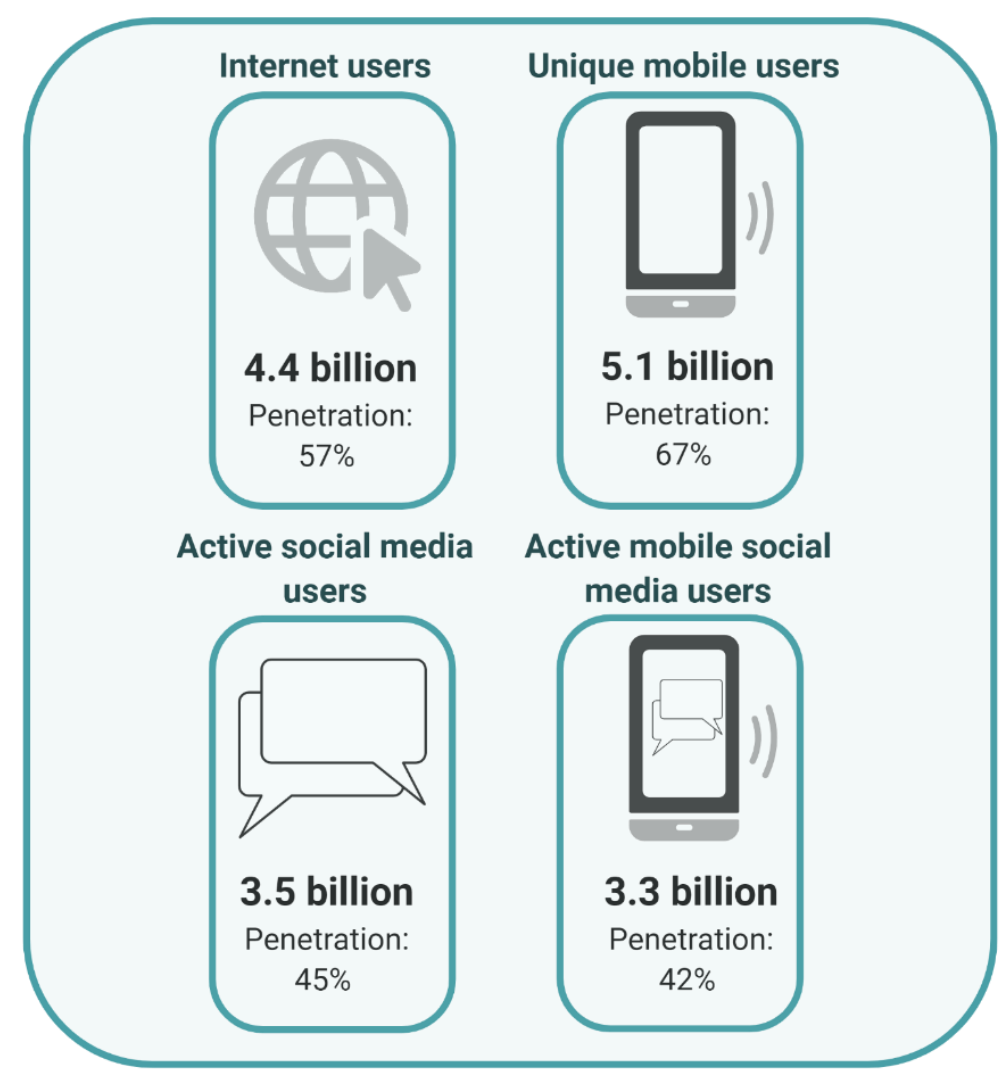


Figure 2. Net number of international migrants (both sexes combined) by global subregion 2015-2020 (thousands). The net number of migrants varies from -6,490,000 in Southern Asia (dark blue) to 5,982,000 in North America (yellow). Data were accessed via the UN Department of Economic and Social Affairs, Population Division database (56).

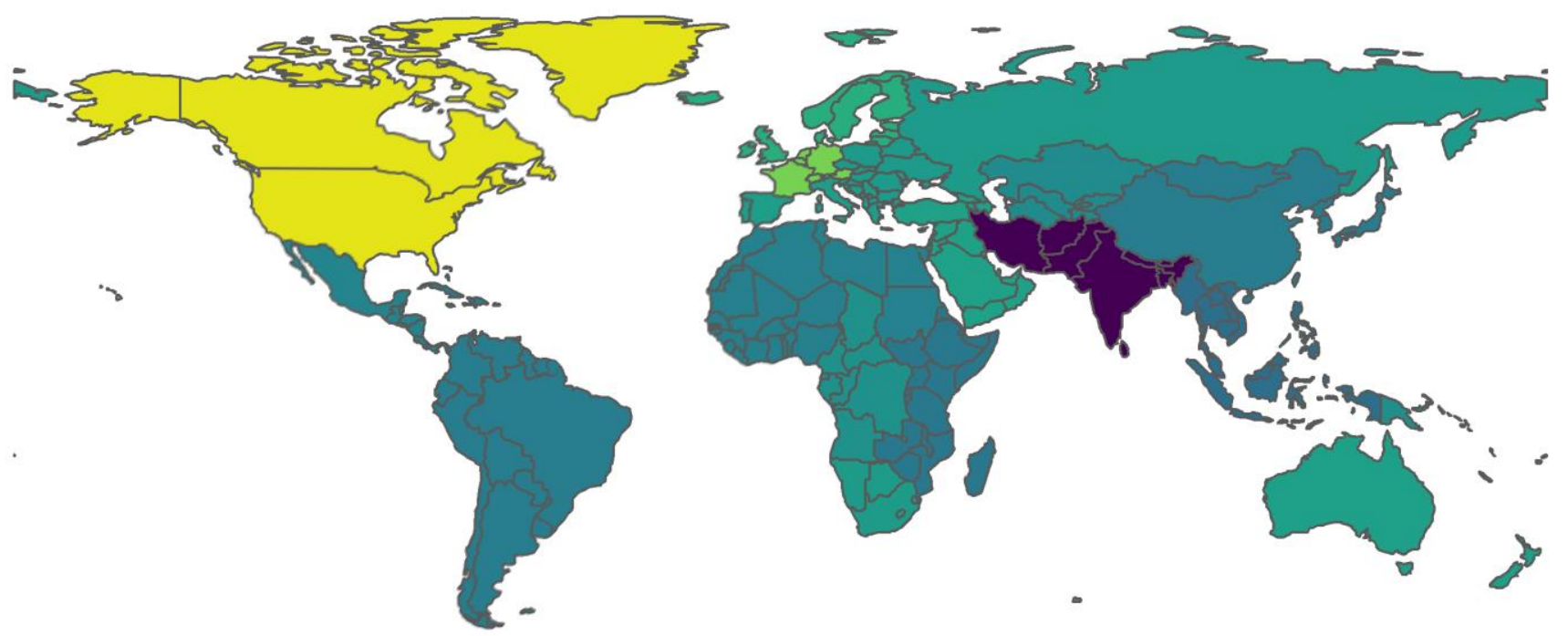

Net number of migrants (thousands)

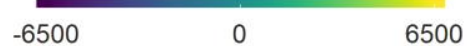


372 Funding and acknowledgements

373 The workshop was supported by a UCL Grand Challenges grant (506002-100-156425).

374 We thank Leroy Clement, Ilan Kelman, Bayes Ahmed, Chris Langridge, Yasna Palmeiro-Silva, 375 Laura Busert, Maheswar Satpathy, Emeline Rougeaux and Alicia Matthews for their help in 376 the organisation of the workshop.

377

378 Author contributions

379 LF and RP led the workshop and took the lead role in writing the report. All authors participated 380 in discussion sessions at the workshop and contributed to the report. Authors 3-10 are listed 381 alphabetically.

382

383 Declarations and conflicts of interest

384 All other authors declare no conflicts of interest in connection to this article.

\section{Open data and data availability}

387 No further data were used in addition to referenced works. 
1. UNHCR. Global Trends: Forced displacements in 2015. Geneva, Sw; 2015.

2. Abubakar I, Aldridge RW, Devakumar D, Orcutt M, Burns R, Barreto ML, et al. The UCL-Lancet Commission on Migration and Health: the health of a world on the move. The Lancet. 2018 Dec 15;392(10164):2606-54.

3. UN. Global Compact for Safe, Orderly and Regular Migration. 2018.

4. IOM. Data bulletin-big data and migration. Ispra: International Organization for Migration; 2018. Available from:

https://publications.iom.int/system/files/pdf/issue_5_big_data_and_migration.pdf [Accessed 2020 Mar 20]

5. Fleming L, Depledge M, Leonelli S, Gordon-Brown H, Leonardi G, Golding B, et al. Big Data in Environment and Human Health. Oxf Res Encycl Environ Sci. 2017; July:1-27.

6. Hay SI, George DB, Moyes CL, Brownstein JS. Big Data Opportunities for Global Infectious Disease Surveillance. PLoS Med. 2013;10(4):2-5.

7. Lu X, Bengtsson L, Holme P. Predictability of population displacement after the 2010 Haiti earthquake. Proc Natl Acad Sci. 2012; 109(29):11576-11581

8. Wilson R, Erbach-Schoenberg E zu, Albert M, Power D, Tudge S, Gonzalez M, et al. Rapid and Near Real-Time Assessments of Population Displacement Using Mobile Phone Data Following Disasters: The 2015 Nepal Earthquake. PLOS Curr Disasters. 2016 Feb 24

9. Lu X, Wrathall DJ, Sundsøy PR. Detecting climate adaptation with mobile network data in Bangladesh : anomalies in communication, mobility and consumption patterns during cyclone Mahasen. Clim Change. 2016;1-15.

10. Lai S, Erbach-Schoenberg E zu, Pezzulo C, Ruktanonchai NW, Sorichetta A, Steele J, et al. Exploring the use of mobile phone data for national migration statistics. Palgrave Commun. 2019 Mar 26;5(1):1-10.

11. Ruktanonchai NW, Ruktanonchai CW, Floyd JR, Tatem AJ. Using Google Location History data to quantify fine-scale human mobility. Int $J$ Health Geogr . 2018 Jul 27;17

12. Spyratos S, Vespe M, Natale F, Weber I, Zagheni E, Rango M. Quantifying international human mobility patterns using Facebook Network data. PLOS ONE. 2019 Oct 24;14(10):e0224134.

13. Palotti J, Adler N, Morales-Guzman A, Villaveces J, Sekara V, Herranz MG, et al. Monitoring of the Venezuelan exodus through Facebook's advertising platform. PLOS ONE. 2020 Feb 21;15(2):e0229175.

14. Peak CM, Wesolowski A, zu Erbach-Schoenberg E, Tatem AJ, Wetter E, Lu X, et al. Population mobility reductions associated with travel restrictions during the 
Ebola epidemic in Sierra Leone: use of mobile phone data. Int $\mathrm{J}$ Epidemiol. 2018 Oct 1;47(5):1562-70.

15. Wesolowski A, Qureshi T, Boni MF, Roe P, Johansson MA, Basit S. Impact of human mobility on the emergence of dengue epidemics in Pakistan. PNAS. 2015;112(38):11887-11892.

16. Van der Geest K, Vrieling A, Dietz T. Migration and environment in Ghana: a cross-district analysis of human mobility and vegetation dynamics. Environ Urban. 2010;22(1):107-123.

17. Lu X, Wrathall DJ, Roe P, Wetter E, lqbal A, Qureshi T, et al. Unveiling hidden migration and mobility patterns in climate stressed regions: A longitudinal study of six million anonymous mobile phone users in Bangladesh. Glob Environ Change. 2016;38:1-7.

18. Sorichetta A, Bird TJ, Ruktanonchai NW, zu Erbach-Schoenberg E, Pezzulo C, Tejedor $\mathrm{N}$, et al. Mapping internal connectivity through human migration in malaria endemic countries. Sci Data. 2016 Aug 16;3(1):1-16.

19. Hauer ME, Fussell E, Mueller V, Burkett M, Call M, Abel K, et al. Sea-level rise and human migration. Nat Rev Earth Environ. 2020 Jan;1(1):28-39.

20. Logar T, Bullock J, Nemni E, Bromley L, Quinn JA, Luengo-Oroz M. PulseSatellite: A tool using human-Al feedback loops for satellite image analysis in humanitarian contexts. ArXiv200110685 Cs Eess. 2020 Jan 28

21. Orcutt M, Spiegel P, Kumar B, Abubakar I, Clark J, Horton R. Lancet Migration: global collaboration to advance migration health. The Lancet. 2020 Feb 1;395(10221):317-9.

22. Kirkpatrick R, Vacarelu F. A Decade of Leveraging Big Data for Sustainable Development. UN Chronicl. 2018;3(December). Available from: https://unchronicle.un.org/article/decade-leveraging-big-data-sustainabledevelopment [Accessed 2020 Feb 11]

23. von Mörner M. Application of Call Detail Records - Chances and Obstacles. Transp Res Procedia. 2017;25:2233-41.

24. de Montjoye Y-A, Gambs S, Blondel V, Canright G, de Cordes N, Deletaille S, et al. On the privacy-conscientious use of mobile phone data. Sci Data. 2018 Dec 11;5(1):1-6.

25. Verhulst SG, Young A. The Potential and Practice of Data Collaboratives for Migration. Stanford Social Innovation Review. 2018. Available from: https://ssir.org/articles/entry/the_potential_and_practice_of_data_collaboratives _for_migration [Accessed 2020 Mar 19]

26. Wesolowski A, Eagle N, Noor AM, Snow RW, Buckee CO. The impact of biases in mobile phone ownership on estimates of human mobility. J R Soc Interface. 2013 Apr 6;10(81):20120986. 
27. Welcome - Humanitarian Data Exchange. Available from: https://data.humdata.org/ [Accessed 2020 Jun 18]

28. Vale S. Big Data Sandbox. UNECE. 2016. Available from: http://www1.unece.org/stat/platform/display/bigdata/Sandbox [Accessed 2020 Mar 19]

29. Parker B. New UN deal with data mining firm Palantir raises protection concerns. The New Humanitarian. 2019. Available from: https://www.thenewhumanitarian.org/news/2019/02/05/un-palantir-deal-datamining-protection-concerns-wfp [Accessed 2020 Mar 19]

30. Oroz ML. From big data to humanitarian-in-the-loop algorithms. UNHCR Innovation. 2018. Available from: https://www.unhcr.org/innovation/big-datahumanitarian-loop-algorithms/ [Accessed 2020 Feb 11]

31. IOM. Workshop Report on Forecasting Human Mobility in Contexts of Crises. Berlin: German Federal Foreign Office (FFO) and the International Organization for Migration (IOM); 2019 Oct

32. Winowatan M. The Emergence of Data Collaboratives...in Numbers. The Governance Lab. 2018. Available from: http://thegovlab.org/the-emergence-ofdata-collaboratives-in-numbers/ [Accessed 2020 Mar 20]

33. NetHope Blog. Unlocking insights from data: Collaboration with private sector creates cutting-edge maps for disaster response - NetHope. 2018. Available from: https://nethope.org/2018/09/10/unlocking-insights-from-data-collaborationwith-private-sector-creates-cutting-edge-maps-for-disaster-response/ [Accessed 2020 Mar 20]

34. Martin S, Ferris E, Kumari K, Bergmann J. The Global Compacts and Environmental Drivers of Migration. KNOMAD; 2018. Report No.: Policy Brief 11.

35. IOM. International Migration Law: Glossary on Migration. Geneva: International Organization for Migration; 2019. Available from: https://www.iom.int/glossarymigration-2019 [Accessed 2020 Mar 30]

36. Disaster Displacement. Key Definitions. Platform on Disaster Displacement. 2020. Available from: https://disasterdisplacement.org/the-platform/keydefinitions [Accessed 2020 Mar 30]

37. Ionesco D, Mokhnacheva D, Gemenne F. The Atlas of Environmental Migration. 1st ed. Oxon, UK: Routledge; 2017.

38. Oakes R, Banerjee S, Warner K. Chapter 9: Human Mobility and Adaptation to Environmental Change. In: World Migration Report 2020. Geneva: United Nations University Institute for Environment and Human Security, International Organization for Migration and UNFCCC Secretariat.; 2019 
39. Davis KF, Bhattachan A, D'Odorico P, Suweis $S$. A universal model for predicting human migration under climate change: examining future sea level rise in Bangladesh. Environ Res Lett. 2018 Jun;13(6):064030.

40. Mueller V, Gray C, Kosec K. Heat stress increases long-term human migration in rural Pakistan. Nat Clim Change. 2014 Mar;4(3):182-5.

41. DTM. South Sudan: Seasonal Floods Analysis. International Organization for Migration; 2019 Oct. Available from: /reports/south-sudan-\%E2\%80\%94seasonal-flooding-maps-november-2019 [Accessed 2020 Mar 30]

42. Lang S, Füreder $P$, Riedler B, Wendt L, Braun A, Tiede D, et al. Earth observation tools and services to increase the effectiveness of humanitarian assistance. Eur J Remote Sens. 2019 Oct 30;0(0):1-19.

43. ESRC. Centre for Longitudinal Studies. UKRI - Economic and Social Research Council. 2020. Available from: https://esrc.ukri.org/research/ourresearch/centre-for-longitudinal-studies/ [Accessed 2020 Mar 17]

44. DTM. DRC - Flow Monitoring Dashboard (November 2019). International Organization for Migration; 2020 Jan

45. World Economic Forum. Civil Society in the Fourth Industrial Revolution: Preparation and Response. Cologny/Geneva; 2019

46. Lamber R, Pinter K, Aigner A, Reiterer M, Kappel K, Grechenig T. Ethical Issues Arising Through Identification and Registration Systems Applied in a European Refugee Camp. In: 2019 9th International Conference on Advanced Computer Information Technologies (ACIT). 2019. p. 320-4.

47. Nawyn SJ. Migration in the Global South: Exploring New Theoretical Territory. Int J Sociol. 2016 Apr 2;46(2):81-4.

48. Arcimaviciene L, Baglama SH. Migration, Metaphor and Myth in Media Representations: The Ideological Dichotomy of "Them" and "Us": SAGE Open. 2018 May 9

49. The Sentinel Project. The Sentinel Project. 2018. Available from: https://thesentinelproject.org/ [Accessed 2020 Mar 20]

50. UNDG. Data Privacy, Ethics and Protection: Guidance Note on Big Data for Achievement of the 2030 Agenda. United Nations Development Group; 2017

51. The Centre for Humanitarian Data. Data Responsibility Guidelines. 2019.

52. Osterwalder A, Pigneur Y. Business Model Generation. Amsterdam: Self Published; 2009.

53. Gooch D, Vasalou A, Benton L. Impact in interdisciplinary and cross-sector research: Opportunities and challenges. J Assoc Inf Sci Technol. 2017;68(2):378-91. 
54. Vogel KM, Tyler BB. Interdisciplinary, cross-sector collaboration in the US Intelligence Community: lessons learned from past and present efforts. Intell Natl Secur. 2019 Sep 19;34(6):851-80.

55. Choi BCK, Pak AWP. Multidisciplinarity, interdisciplinarity and transdisciplinarity in health research, services, education and policy: 1. Definitions, objectives, and evidence of effectiveness. Clin Investig Med Med Clin Exp. 2006 Dec;29(6):351-64.

56. We Are Social, Hootsuite. Global Digital Report 2019. New York; 2019. Available from: https://wearesocial.com/global-digital-report-2019 [Accessed 2020 Apr 1]

57. United Nations, Department of Economic and Social Affairs, Population Division. World Population Prospects 2019, Online Edition. Rev. 1. 2019. 